\title{
Splanchnic and renal elimination and release of catecholamines in cirrhosis. Evidence of enhanced sympathetic nervous activity in patients with decompensated cirrhosis
}

\author{
J H HENRIKSEN, H RING-LARSEN, I-L KANSTRUP, AND N J CHRISTENSEN \\ From the Department of Medicine, Division of Hepatology, and Department of Clinical Physiology, \\ Hvidovre Hospital, and Department of Internal Medicine and Endocrinology, Herlev Hospital, University of \\ Copenhagen, Copenhagen, Denmark
}

SUMMARY Plasma noradrenaline (NA) and adrenaline (A) concentrations were determined in different vascular areas in 32 patients with cirrhosis and in nine controls during a right sided heart, liver, and renal vein catheterisation. The patients were divided into four groups: (I) Compensated (without ascites); (II) Recompensated on diuretic treatment because of former ascites; (III) Decompensated (with ascites) without treatment and (IV) Decompensated on diuretic treatment. Median arterial noradrenaline concentrations were 1.48, 1.07, 2.66, $4 \cdot 14$ and $2.50 \mathrm{nmol} / 1$ in controls, group I, II, III, and IV, respectively, the three last mentioned values being significantly raised $(\mathrm{p}<0.01)$. Median arterial adrenaline concentrations were not significantly increased. In patients arterial-hepatic venous extraction ratios of noradrenaline and adrenaline were on the average $25 \%(\mathrm{p}<0.01)$ and $20 \%(\mathrm{p}<0.02)$ less than those of the controls, indicating a slightly reduced splanchnic elimination of catecholamines in cirrhoses. In controls and group I significant renal venous-arterial noradrenaline differences were absent $(0 \cdot 00$ and 0.03 $\mathrm{nmol} / \mathrm{l})$ while renal venous-arterial noradrenaline differences were significantly increased in groups II, III and IV $(0.47,0.53$ and $0.68 \mathrm{nmol} / 1, \mathrm{p}<0.01)$, indicating a significant net release of noradrenaline from the kidneys in recompensated and decompensated patients. Renal extraction of adrenaline was normal. In conclusion, increased arterial noradrenaline in decompensated and recompensated cirrhosis is only to a limited extent owing to reduced net splanchnic elimination. More likely the increase is caused by release of noradrenaline from the kidneys and possibly other organs indicating enhanced sympathetic nervous tone in these conditions.

Noradrenaline is the neurotransmitter released from axon terminals of sympathetic postganglionic neurones. The amount of noradrenaline escaping into the circulation may be accurately measured by enzymatic isotope derivative techniques, ${ }^{1-3}$ and studies in man have shown that the plasma concentration of noradrenaline is an index of sympathetic nervous activity. ${ }^{3}$ In preliminary studies we have reported increased plasma noradrenaline concentration in patients with cirrhosis, ${ }^{45}$ a finding which has been confirmed by others. ${ }^{6-8}$ The raised plasma

Address for correspondence: Jens H Henriksen, MD, Department of Clinical Physiology, Bispebjerg Hospital, Bispebjerg Bakke 23, DK-2400 Copenhagen NV, Denmark

Received for publication 16 December 1983 noradrenaline in cirrhosis suggests enhanced sympathetic nervous activity in this condition. ${ }^{49}$ Because catecholamines are metabolised in the liver, ${ }^{10}$ however, the increased plasma noradrenaline might be a consequence of decreased hepatic function in patients with liver disease.

The present study was undertaken in order to establish whether the augmented plasma noradrenaline concentration in some patients with cirrhosis is indicative of increased sympathetic nervous activity or merely the result of a diminished hepatic catabolism of catecholamines. Therefore, we determined splanchnic and renal extraction or release of noradrenaline and adrenaline in patients with different stages of cirrhosis and in controls 1034 
during a right sided heart, liver, and renal vein chatheterisation.

\section{Methods}

\section{PATIENTS}

The study comprised 32 patients (six women and 26 men) with cirrhosis confirmed by biopsy. Age ranged from 30-70 years, body height from 157-186 $\mathrm{cm}$, and weight from 53-116 kg. The aetiology was alcohol in 30 cases while unknown in two cases. The patients studied were referred to the following groups: Group I: patients without former or present ascites, (compensated without treatment, $n=10$ ). Group II: patients on diuretic treatment because of former ascites, but without actual signs of ascites at the time of investigation (recompensated, $n=7$ ). Group III: patients with ascites, not on diuretic treatment at the time of investigation (decompensated without treatment, $n=5$ ). Group IV: patients with ascites on diuretic treatment at the time of investigation (decompensated on diuretic treatment, $n=10$ ). Three of the five patients in group III had never been treated with diuretics, in the two remaining patients, diuretics had been discontinued for more than two weeks before the study. The diuretic treatment in group II and IV consisted of spironolactone $(100-200 \mathrm{mg} / \mathrm{d})$ as a basic therapy. According to clinical improvement bumetanide $(2-4 \mathrm{mg} / \mathrm{d})$ was given individually. In addition the patients in group II, III and IV received a sodium restricted diet $(40 \mathrm{mmol} / \mathrm{d})$ but unrestricted water intake. Routine laboratory tests are shown in Table 1.

All patients had been hospitalised for several days and were considered to be in a stable stage of their disease without signs of actual alcoholic consumption or withdrawal symptoms.

None of the patients had arterial hypertension, episodes of hypoglycaemia, diabetes mellitus, thyroid disorders, cardiac failure, duodenal ulcer or organic renal disease. None of the patients had experienced gastrointestinal bleeding or hepatic encephalopathy.

In the catheterisation study nine persons served as controls (one woman and eight men). Age ranged from $22-52$ years, body height from $160-185 \mathrm{~cm}$, and weight from 58-88 kg. Six were normal volunteers, and three were patients with no abnormal haemodynamic findings (two with fatty liver, one with functional heart murmur). Controls in the peripheral venous sampling study were seven other normal volunteers (two women and five men). The age ranged from 32-68 years, body height from $150-180 \mathrm{~cm}$, and weight from $56-83 \mathrm{~kg}$.

Patients and controls consented to participate in the investigations. The study was approved by the hospital ethical committee, and no complications or side effects were seen during the investigative procedures.

Plasma noradrenaline and adrenaline concentrations were determined by an enzymatic isotopederivate technique as described previously. ${ }^{2}$ The plasma volume required is $50 \mu \mathrm{l}$. The sensitivity is approximately $5 \cdot 10^{-6} \mathrm{nmol}$ per sample $(=50 \mu \mathrm{l})$. The intra-assay coefficient of variation is $8 \%$ at concentrations about $1 \mathrm{nmol} / \mathrm{l}$ and below $8 \%$ at higher concentrations. Plasma samples with known amounts of catecholamines added were analysed in each assay.

The functional liver cell mass was estimated by the galactose elimination capacity, as described by Tygstrup. ${ }^{11}$

\section{CATHETERISATION STUDY}

A right sided venous catheterisation was performed under local anaesthesia in the supine, fasting person from an antecubital vein or in a few cases by Seldinger technique from the right femoral vein under fluoroscopic control as previously described. ${ }^{12}$ A short indwelling polyethylene catheter was placed in the femoral artery by Seldinger technique. Pressures were measured in the wedged and free hepatic vein, and in the femoral artery by a capacitance transducer (Simonsen and Weel), the zero pressure level being the midaxillary line. Heart rate was determined from the ECG.

Estimated hepatic blood flow was measured by the indocyanine green constant infusion technique, as described by Winkler and Tygstrup. ${ }^{13}$ Preceded by a priming dose $(2 \mathrm{mg})$, a constant infusion of indocyanine green (Cardio-Green ${ }^{\circledR}, 0.2 \mathrm{mg} / \mathrm{min}$, calibrated Dich-pump) in a 5\% human albumin preparation was given during one hour. Indocyanine green concentration in arterial and hepatic venous plasma (range 0.3 to $2.0 \mu \mathrm{mol} / \mathrm{l}$ ) was measured spectrophotometrically (Zeiss-PMQ-II) at 800 and $900 \mathrm{~nm}$ for turbidity correction, ${ }^{13}$ the intra-assay coefficient of variation being below $2 \%$. Estimated hepatic plasma flow was calculated according to Winkler and Tygstrup ${ }^{13}$ and the estimated hepatic blood flow was calculated from the arterial haematocrit.

Plasma samples for noradrenaline and adrenaline determination were obtained simultaneously from aretery (a)/hepatic vein (hv) and artery/right renal vein (rv). To avoid caval reflux the samples were drawn slowly (sampling time about one minute) and the catheter tip was at least $6 \mathrm{~cm}$ into the hepatic vein. Splanchnic extraction ratio of noradrenaline and adrenaline was calculated as (a-hv)/a. Net splanchnic clearance of noradrenaline and 
adrenaline was calculated as estimated hepatic plasma flow multiplied by $(\mathrm{a}-\mathrm{hv}) / \mathrm{a}$, and net splanchnic elimination rate was determined as estimated hepatic plasma flow multiplied by $(a-h v)$.

Renal extraction ratio of adrenaline was calculated as (a-rv)/a. Renal release of noradrenaline into systemic circulation was expressed as a ratio: rv/a or as renal venous-arterial concentration difference: rv-a.

PERIPHERAL VENOUS BLOOD SAMPLING STUDY After an overnight fast, a small polyethylene catheter was placed in an antecubital vein. Venous blood was drawn for determination of catecholamines after patients and controls had rested in the supine position for at least one hour.

\section{STATISTICAL EVALUATION}

The significance of differences between median values were tested by Wilcoxon's rank tests for paired or grouped data. Correlations were tested by the method of least squares. $p<0.05$ was considered significant.

\section{Results}

PERIPHERAL VENOUS BLOOD SAMPLING STUDY The results are summarised in Table 2 . In compensated patients (group I), plasma noradrenaline concentration was identical to that of normal controls (median $1.36 \mathrm{nmol} / \mathrm{l}$ ). In recompensated patients (group II) and decompensated patients (group III and IV) significantly increased values of plasma noradrenaline were found $(2.31,4.97,3.13 \mathrm{nmol} / \mathrm{l}$, respectively $v s$ controls $1.36 \mathrm{nmol} / 1, \mathrm{p}<0 \cdot 01)$. As a whole plasma adrenaline concentration was not increased in patients with cirrhosis compared with that of normal controls $(0.27$ vs $0.33 \mathrm{nmol} / \mathrm{l}, \mathrm{NS})$.

\section{CATHETERISATION STUDY}

As seen in Table 2 the concentrations of plasma noradrenaline and adrenaline in arterial blood samples obtained during the catheterisation study were quite similar to those of the peripheral venous blood sampling study.

The results of blood pressure, heart rate, estimated hepatic blood flow, indocyanine green extraction and clearance are summarised in Table 3.

\section{NORADRENALINE}

The results of plasma noradrenaline from artery/ hepatic vein samples and artery/renal vein samples are shown in Figures 1 and 2. Extraction and release of noradrenaline and adrenaline are summarised in Tables 4 to 6 .

Considerable amounts of noradrenaline were extracted by the splanchnic area. In patients the splanchnic extraction ratio of noradrenaline was on the average $25 \%$ below that of controls $(\mathrm{p}<0.01)$, but any significant difference between the groups of patients was absent, see Table 4 . The net splanchnic plasma clearance of noradrenaline was $435 \mathrm{ml} / \mathrm{min}$ and $262 \mathrm{ml} / \mathrm{min}$ in controls $(\mathrm{n}=8)$ and patients $(n=22)$, respectively $(p<0 \cdot 01)$, see Table 5 .

In controls and group I patients no significant

Table 2 Plasma noradrenaline (NA) and adrenaline $(A)$ in control subjects and different groups of patients with cirrhosis

\begin{tabular}{|c|c|c|c|c|c|c|}
\hline & \multicolumn{2}{|c|}{ Peripheral venous samples } & \multirow[b]{2}{*}{ no } & \multicolumn{2}{|c|}{ Arterial samples } & \multirow[b]{2}{*}{ no } \\
\hline & $\begin{array}{l}\text { NA } \\
\text { nmol/l }\end{array}$ & $\begin{array}{l}A \\
\text { nmolll }\end{array}$ & & $\begin{array}{l}\text { NA } \\
\text { nmol/l }\end{array}$ & $\begin{array}{l}A \\
\text { nmolll }\end{array}$ & \\
\hline Controls (C) & $\begin{array}{l}1 \cdot 36^{*} \\
(0 \cdot 53-2 \cdot 19)\end{array}$ & $\begin{array}{l}0.33^{*} \\
(0 \cdot 00-0.82)\end{array}$ & 7 & $\begin{array}{l}1.48 \dagger \\
(0.89-3.02)\end{array}$ & $\begin{array}{l}0.33 \dagger \\
(0.16-0.66)\end{array}$ & 9 \\
\hline Cirrhosis & & & & & & \\
\hline II & $\begin{array}{l}1 \cdot 36 \\
(0 \cdot 47-3 \cdot 25)\end{array}$ & $\begin{array}{l}0.16 \\
(0 \cdot 00-0 \cdot 55)\end{array}$ & 7 & $\begin{array}{l}1.07 \\
(0 \cdot 65-2 \cdot 54)\end{array}$ & $\begin{array}{l}0.27 \\
(0 \cdot 11-0.77)\end{array}$ & 10 \\
\hline II & $\begin{array}{l}2 \cdot 31 \ddagger \\
(1 \cdot 30-3 \cdot 55)\end{array}$ & $\begin{array}{l}0.27 \\
(0.05-0.66)\end{array}$ & 7 & $\begin{array}{l}2 \cdot 66 \ddagger \\
(1 \cdot 30-3 \cdot 91)\end{array}$ & $\begin{array}{l}0.27 \\
(0.05-0.93)\end{array}$ & 7 \\
\hline III & $\begin{array}{l}4.97 \ddagger \\
(2 \cdot 54-9 \cdot 47)\end{array}$ & $\begin{array}{l}0 \cdot 38 \\
(0 \cdot 16-1 \cdot 42)\end{array}$ & 5 & $\begin{array}{l}4 \cdot 14 \ddagger \\
(2 \cdot 01-9 \cdot 47)\end{array}$ & $\begin{array}{l}0.71 \\
(0.44-1.58)\end{array}$ & 5 \\
\hline $\begin{array}{l}\text { IV } \\
\text { Total (I-IV) }\end{array}$ & $\begin{array}{l}3 \cdot 13 \ddagger \\
(1 \cdot 54-6 \cdot 15) \\
2 \cdot 54 \S\end{array}$ & $\begin{array}{l}0 \cdot 25 \\
(0 \cdot 11-1 \cdot 91) \\
0 \cdot 27\end{array}$ & 5 & $\begin{array}{l}2 \cdot 50 \ddagger \\
(1.48-9.94) \\
2 \cdot 40 \S\end{array}$ & $\begin{array}{l}0 \cdot 25 \\
(0 \cdot 11-3 \cdot 17) \\
0 \cdot 27\end{array}$ & 10 \\
\hline
\end{tabular}

Values in the table are medians, ranges are in parentheses.

* Seven normal subjects

† Six normal subjects and three patients without cirrhosis (see text)

¥ Significantly different from controls and patients with compensated cirrhosis $(p<0.01)$

$\S$ Significantly different from controls $(p<0 \cdot 01)$

I I-IV, see Table 1. 
Table 3 Haemodynamic data in control subjects and different groups of patients with cirrhosis

\begin{tabular}{|c|c|c|c|c|c|c|c|}
\hline & \multirow{2}{*}{$\begin{array}{l}\text { Mean arterial } \\
\text { blood pressure } \\
\mathrm{mmHg}\end{array}$} & \multirow[b]{2}{*}{$\begin{array}{l}\text { Heart } \\
\text { rate/min }\end{array}$} & \multirow{2}{*}{$\begin{array}{l}\text { Hepatic } \\
\text { blood flow } \dagger \\
\text { l/min }\end{array}$} & \multicolumn{2}{|c|}{ Indocyanine Greent } & \multirow{2}{*}{$\begin{array}{l}\text { Wedged hepatic } \\
\text { vein pressure } \\
\mathrm{mmHg}\end{array}$} & \multirow{2}{*}{$\begin{array}{l}\text { Free hepatic } \\
\text { vein pressure } \\
\mathrm{mmHg}\end{array}$} \\
\hline & & & & $\begin{array}{l}\text { Clearance } \\
\mathrm{mllmin}\end{array}$ & Extractionsई & & \\
\hline Controls $(\mathrm{n}=9)$ & $\begin{array}{l}91 \\
(75-115)\end{array}$ & $\begin{array}{l}66 \\
(55-78)\end{array}$ & $\begin{array}{l}1 \cdot 20 \\
(0 \cdot 81-1 \cdot 80)\end{array}$ & $\begin{array}{l}577 \\
(370-883)\end{array}$ & $\begin{array}{l}0.80 \\
(0.61-0.87)\end{array}$ & $\begin{array}{l}7 \cdot 3 \\
(5 \cdot 5-9)\end{array}$ & $\begin{array}{l}3 \cdot 5 \\
(-1 \cdot 5-5 \cdot 5)\end{array}$ \\
\hline \multicolumn{8}{|c|}{ Cirrhosis $(\mathrm{n}=32)$} \\
\hline$I^{*}$ & $\begin{array}{l}88 \\
(77-107)\end{array}$ & $\begin{array}{l}74 \\
(56-92)\end{array}$ & $\begin{array}{l}1 \cdot 11 \\
(0 \cdot 57-2 \cdot 10)\end{array}$ & $\begin{array}{l}345 \ddagger \\
(125-450)\end{array}$ & $\begin{array}{l}0.46 \\
(0.20-0.71)\end{array}$ & $\begin{array}{l}15 \ddagger \\
(6-21)\end{array}$ & $\begin{array}{l}4 \\
(2-9)\end{array}$ \\
\hline II & $\begin{array}{l}81 \\
(60-91)\end{array}$ & $\begin{array}{l}78 \ddagger \\
(62-120)\end{array}$ & $\begin{array}{l}1 \cdot 20 \\
(0 \cdot 2-1 \cdot 73)\end{array}$ & $\begin{array}{l}356 \\
(100-640)\end{array}$ & $\begin{array}{l}0.48 \\
(0.23-0.70)\end{array}$ & $\begin{array}{l}20 \ddagger \\
(9-27)\end{array}$ & 6 \\
\hline III & $\begin{array}{l}78 \\
(70-100)\end{array}$ & $\begin{array}{l}106 \ddagger \\
(86-110)\end{array}$ & $\begin{array}{l}1 \cdot 35 \\
(1 \cdot 13-1 \cdot 55)\end{array}$ & $\begin{array}{l}274 \\
(72-476)\end{array}$ & $\begin{array}{l}0 \cdot 34 \ddagger \\
(0 \cdot 1-0 \cdot 58)\end{array}$ & $\begin{array}{l}29 \ddagger \\
(26-49)\end{array}$ & $\begin{array}{l}7 \ddagger \\
(6-18)\end{array}$ \\
\hline IV & $\begin{array}{l}81 \\
(68-85)\end{array}$ & $\begin{array}{l}90 \ddagger \\
(74-104)\end{array}$ & $\begin{array}{l}1.49 \\
(0.49-2 \cdot 41)\end{array}$ & $\begin{array}{l}197 \ddagger \\
(79-347)\end{array}$ & $\begin{array}{l}0.36 \ddagger \\
(0.17-0.69)\end{array}$ & $\begin{array}{l}27 \ddagger \\
(23-35)\end{array}$ & $\begin{array}{l}10 \ddagger \\
(6-14)\end{array}$ \\
\hline
\end{tabular}

Values in the table are medians, ranges are in parentheses.

* I-IV, see Table 1

† Values from 22 patients with cirrhosis

$\ddagger$ Significantly different from controls

§ Splanchnic extraction: (artery-liver vein)/artery.

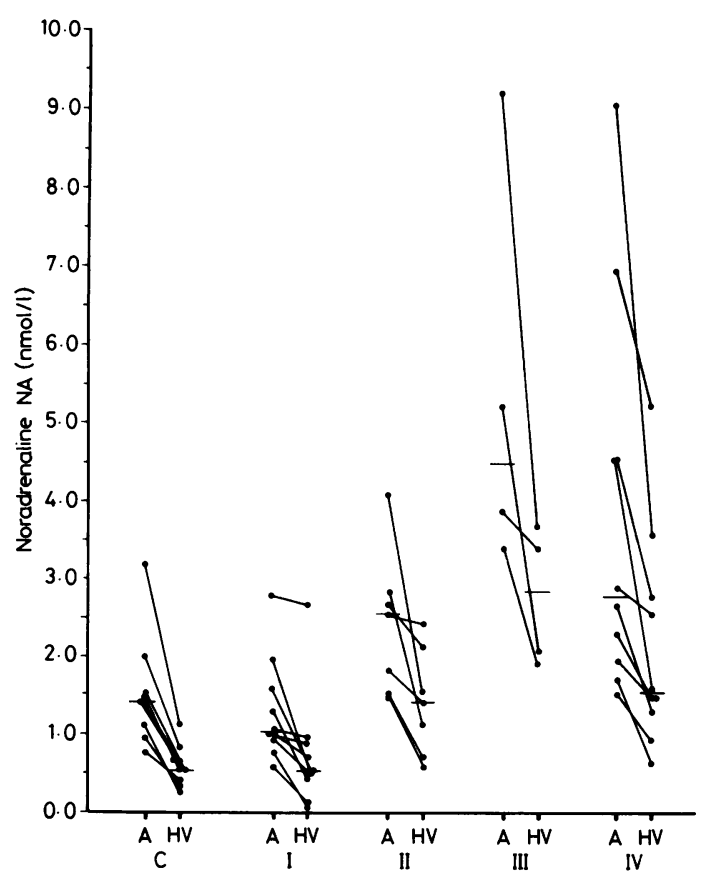

Fig. 1 Splanchnic net extraction of noradrenaline (NA). Plasma noradrenaline (ordinate) from simultaneously obtained samples from artery $(A)$ and hepatic vein $(H V)$ in different groups of patients with cirrhosis: group I: compensated, group II: recompensated on diuretic treatment, group III: ascitic patients without treatment, group IV: ascitic patients on diuretic treatment, and group $C$ : controls. Concentration of noradrenaline in hepatic vein is significantly below that of artery in all groups. Transverse bars indicate medians.

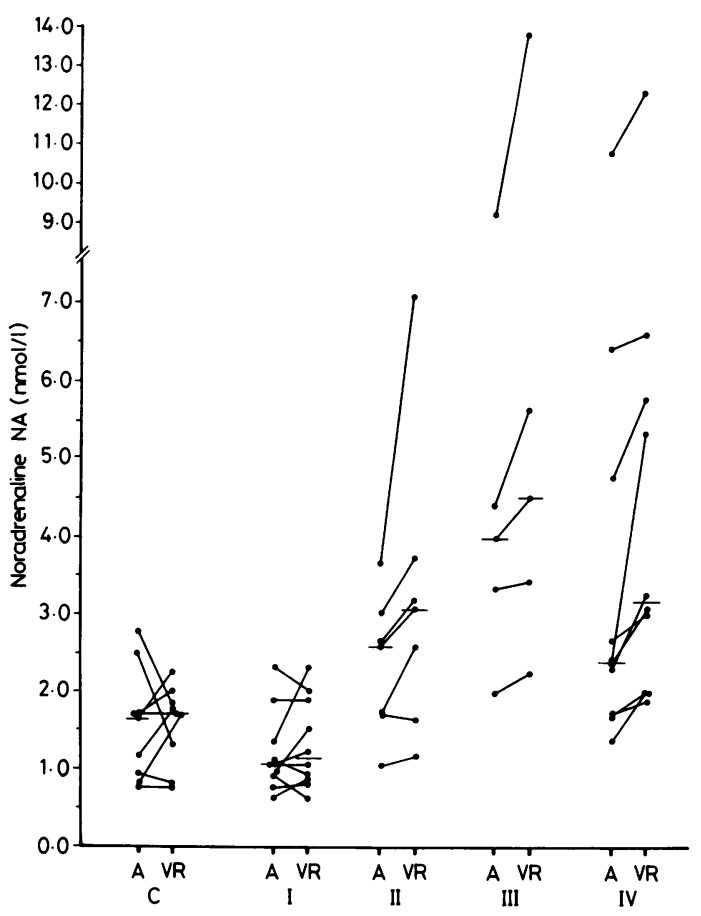

Fig. 2 Renal net release of noradrenaline (NA) into systemic circulation. Plasma noradrenaline (ordinate) from simultaneously obtained samples from artery $(A)$ and right renal vein $(V R)$ in different groups of patients with cirrhosis and controls (see legend to Fig. 1). Concentration of noradrenaline in renal vein is significantly above that of artery in recompensated (group II) and decompensated (ascitic) patients (group III and IV), but not in controls (C) or compensated patients (I). Transverse bars indicate medians. 
Table 4 Splanchnic and renal net extraction or release of noradrenaline (NA) in control subjects and different groups of patients with cirrhosis

\begin{tabular}{|c|c|c|c|c|}
\hline & \multicolumn{2}{|c|}{ Splanchnic System } & \multicolumn{2}{|l|}{ Kidney } \\
\hline & $(a-v) / a \dagger$ & $\begin{array}{l}(a-v) \\
n m o l / l\end{array}$ & $v / a$ & $\begin{array}{l}(v-a) \\
n m o l / l\end{array}$ \\
\hline Controls* & $\begin{array}{l}0.63 \\
(0.46-0.79)\end{array}$ & $\begin{array}{l}0 \cdot 88 \\
(0 \cdot 36-2 \cdot 07)\end{array}$ & $\begin{array}{l}1 \cdot 00 \\
(0 \cdot 52-2 \cdot 1)\end{array}$ & $\begin{array}{l}0.00 \\
(-1 \cdot 18-0.89)\end{array}$ \\
\hline \multicolumn{5}{|c|}{ Cirrhosis* } \\
\hline I & $\begin{array}{l}0.56 \\
(0.04-0.92)\end{array}$ & $\begin{array}{l}0 \cdot 44 \\
(0 \cdot 12-1 \cdot 48)\end{array}$ & $\begin{array}{l}1.04 \\
(0 \cdot 69-1 \cdot 7)\end{array}$ & $\begin{array}{l}0.03 \\
(-0.30-0.77)\end{array}$ \\
\hline II & $\begin{array}{l}0.54 \\
(0.05-0.62)\end{array}$ & $\begin{array}{l}0 \cdot 83 \\
(0 \cdot 12-2 \cdot 54)\end{array}$ & $\begin{array}{l}1 \cdot 20 \\
0 \cdot 97-1 \cdot 9)\end{array}$ & $\begin{array}{l}0.47 \ddagger \\
(-0.06-3.37)\end{array}$ \\
\hline III & $\begin{array}{l}0.529 \\
(0 \cdot 12-0.60)\end{array}$ & $\begin{array}{l}1.48 \\
(0 \cdot 47-5 \cdot 56)\end{array}$ & $\begin{array}{l}1.21 \\
(1 \cdot 00-1 \cdot 51)\end{array}$ & $\begin{array}{l}0.53 \ddagger \\
(0 \cdot 00-4 \cdot 67)\end{array}$ \\
\hline IV & $\begin{array}{l}0.39 \\
(0.12-0.62) \S\end{array}$ & $\begin{array}{l}1 \cdot 24 \\
(0 \cdot 36-5 \cdot 50)\end{array}$ & $\begin{array}{l}1 \cdot 20 \\
(1 \cdot 03-2 \cdot 2)\end{array}$ & $\begin{array}{l}0 \cdot 68 \ddagger \\
(0 \cdot 18-2 \cdot 90)\end{array}$ \\
\hline
\end{tabular}

Values in the table are medians, ranges are in parentheses.

* Controls, I-IV, see Table 1

$\dagger \mathrm{a}$ : arterial concentration, $v$ : venous concentration, $(\mathrm{a}-\mathrm{v}) / \mathrm{a}$ : net splanchnic extraction ratio of noradrenaline, $v / a$ : renal venous arterial ratio of noradrenaline

¥ Significantly different from zero, controls and group I, patients $(\mathrm{p}<0.01)$

$\S$ The median value of all cirrhotic patients: 0.48 is significantly different from that of controls $(p<0.01)$

I $\mathrm{n}=4$.

renal venous-arterial differences of plasma noradrenaline concentration were found (median 0.00 $\mathrm{nmol} / \mathrm{l}$ and $0.03 \mathrm{nmol} / \mathrm{l}$, respectively). Median renal venous-arterial noradrenaline difference was 0.47 , 0.53 and $0.68 \mathrm{nmol} / \mathrm{l}$ in patients in group II, III, and IV, respectively. All were significantly different from zero $(p<0.01)$ and significantly different from values obtained in the controls $(p<0 \cdot 01)$ and the compensated group of patients (group I, $\mathrm{p}<0.01$ ), see Table 4. No significant difference could be detected between untreated decompensated

Table 5 Net splanchnic clearance of noradrenaline (NA) and adrenaline $(A)$ in control subjects and patients with cirrhosis

\begin{tabular}{lll}
\hline & \multicolumn{2}{l}{ Net splanchnic clearance $(\mathrm{ml} / \mathrm{min})$} \\
\cline { 2 - 3 } & $N A$ & $A$ \\
\hline Controls $(\mathrm{n}=8)$ & 435 & 490 \\
& $(295-644)$ & $(61-990)$ \\
Cirrhosis* $^{*}(\mathrm{n}=22)$ & $262 \dagger$ & 491 \\
& $(25-556)$ & $(0-1260)$ \\
\hline
\end{tabular}

Values in the table are medians, ranges are in parentheses. * No significant differences were found between the different groups of cirrhotic patients I, II, III and IV

(NA: 262, 202, 245 and $375 \mathrm{ml} / \mathrm{min}$, respectively; A: 456, 285, 532 and $538 \mathrm{ml}$ respectively).

+ Significantly different from controls $(p<0.02)$
Table 6 Splanchnic and renal net extraction of adrenaline $(A)$ in control subjects and patients with cirrhosis

\begin{tabular}{lll}
\hline & $\begin{array}{l}\text { Splanchnic System } \\
(a-v) / a^{*}\end{array}$ & $\begin{array}{l}\text { Kidney } \\
(a-v) / a\end{array}$ \\
\hline Controls $(\mathrm{n}=9)$ & $0 \cdot 88$ & $0 \cdot 50 \dagger$ \\
Cirrhosis $(\mathrm{n}=32)$ & $(0 \cdot 15-1 \cdot 0)$ & $(0 \cdot 00-0 \cdot 67)$ \\
& $0 \cdot 67 \ddagger \S$ & $0 \cdot 50 \dagger$ \\
$(0 \cdot 00-1 \cdot 0)$ & $(0 \cdot 00-0 \cdot 83)$ \\
\hline
\end{tabular}

Values in the Table are medians, ranges are in parentheses.

* $a$ : arterial concentration, $v$ : venous concentration $(a-v) / a$ : net extraction ratio.

† Significantly different from splanchnic system $(p<0.05)$

$\ddagger$ Significantly different from controls $(p<0 \cdot 02)$

$\S n=31$.

patients and those on diuretic treatment.

As seen from Figure 3, a positive correlation between wedge-minus-free hepatic vein pressure and arterial noradrenaline was present in the cirrhotic patients $(r=0.75$ (linear), $r=0.81$ ( $\log$ noradrenaline), $\mathrm{p}<0.001)$. A weaker positive correlation was observed between renal venousarterial noradrenaline difference and wedgedminus-free hepatic vein pressure $(\mathrm{r}=0.58$ (linear), $r=0.54(\log ), p<0.01$, see Figure 4). No significant correlation was found between plasma noradrenaline concentration on one side and serum sodium concentration, galactose elimination capacity, indocyanine green clearance, splanchnic indocyanine green extraction, estimated hepatic

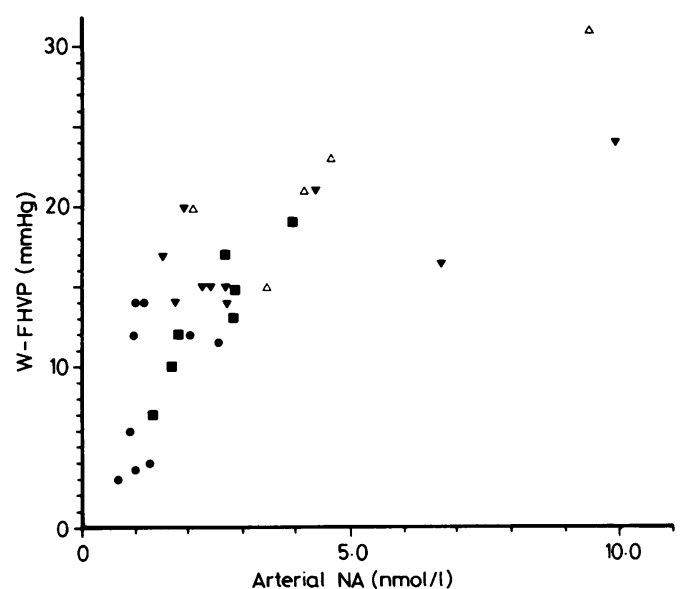

Fig. 3 Relationship between arterial plasma concentrations of noradrenaline (NA, abscissa) and wedged-minus-free hepatic vein pressure (W-FHVP) in different groups of patients with cirrhosis ( $r=0.75$ (linear), $r=0.81$ (log),

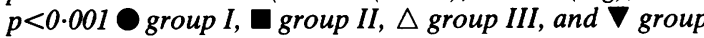
$I V$, see legend to Fig. 1 and text). 


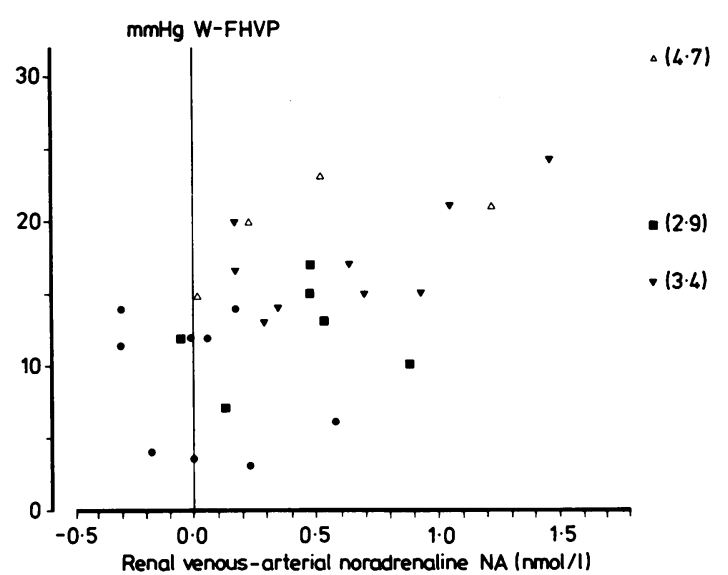

Fig. 4 Relationship between renal venous-arterial plasma noradrenline (NA) concentration difference (abscissa) and wedged-minus-free hepatic vein pressure (W-FHVP ordinate, $r=0.58$ (linear), $r=0.54(\log ), p<0.01)$. For symbols, see legend to Fig. 3.

blood flow, or arterial blood pressure on the other side.

Splanchnic net elimination rate of noradrenaline is illustrated in Figure 5.

\section{ADRENALINE}

Adrenaline was significantly extracted by the splanchnic area as well as by the kidney (see Table 6). In patients with cirrhosis the splanchnic extraction ratio of adrenaline was decreased by $20 \%$ as compared with that of normals $(p<0 \cdot 02)$. No significant change in net splanchnic clearance or net elimination rate was found, however, see Table 5 and Figure 5. The renal extraction ratio of adrenaline was similar in controls $(0.50)$ and patients $(0 \cdot 50)$. These values were lower than those of the splanchnic area both in controls $(-43 \%$, $\mathrm{p}<0.05)$ and in patients $(-23 \%, \mathrm{p}<0.05)$.

\section{Discussion}

The present findings confirm that arterial and peripheral venous plasma noradrenaline concentrations are substantially raised in patients with decompensated and recompensated cirrhosis but almost normal in compensated patients. This is apparently not because of diuretic treatment as untreated patients (group III) had equally high values of arterial noradrenaline compared with treated patients (group IV). Moreover, intravenous injection of loop-diuretics only changes plasma noradrenaline slightly in supine patients with cirrhosis (unpublished results). The catheterisation procedure could be a potential cause of raised noradrenaline concentrations. This seems unlikely as samples obtained from simple peripheral venous puncture did not deviate significantly from those obtained during catheterisation. This is in keeping with earlier experience from our laboratory. ${ }^{414}$ The raised plasma noradrenaline in resting supine position cannot be explained by known exogeneous stimulations such as smoking, alcohol intake, alcoholic withdrawal or hypoglycaemia, because none of these factors were present in our patients. Neither did the patients have other disorders, known to be associated with increased plasma noradrenaline. ${ }^{3} 14$
Fig. 5 Estimated net splanchnic elimination rate of noradrenaline (NA) and adrenaline $(A)$, ordinate, in relation to arterial concentration, abscissa. For symbols, see legend to Fig. 3 . controls.
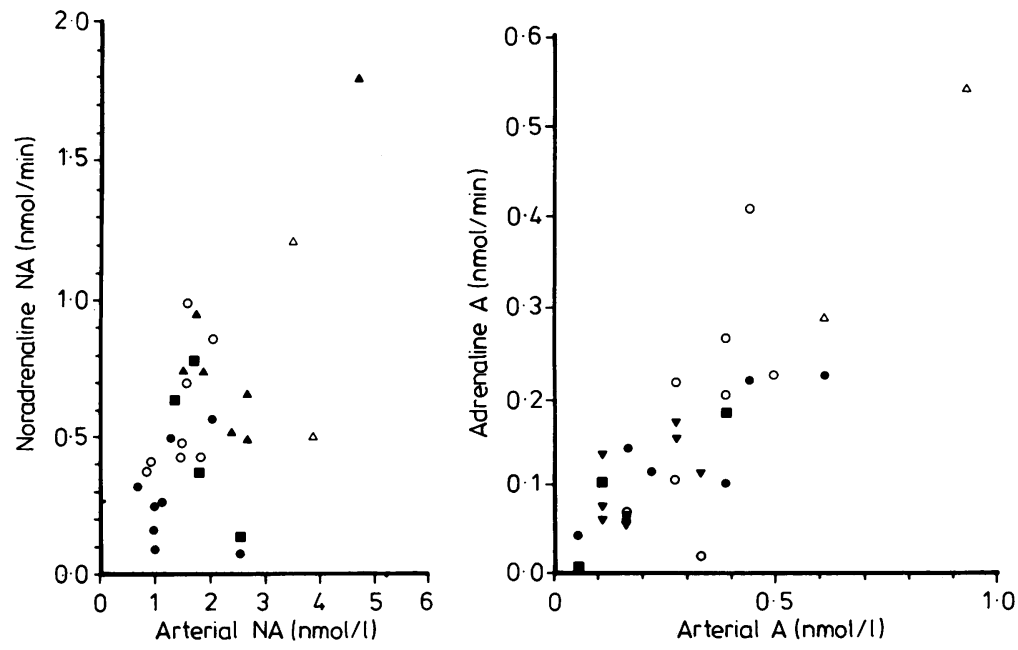
Liver cell function, as evaluated by the galactose elimination capacity, indocyanine green clearance and splanchnic indocyanine green extraction (see Table 1 and 3) were only moderately decreased. This is probably due to exclusion of patients with gastrointestinal bleeding and hepatic encephalopathy. The extracellular volume is increased in decompensated cirrhosis, but an increased volume of distribution of noradrenaline and adrenaline cannot explain the increased arterial concentrations.

Figure 5 shows the relationship between arterial plasma concentration and estimated splanchnic net elimination rate of noradrenaline and adrenaline. No signs of an enzymatic limitation $\left(\mathrm{V}_{\max }\right.$ level) of the splanchnic elimination of catecholamines are present. During steady state, whole body noradrenaline release rate equals elimination rate, and the arterial plasma concentration of noradrenaline may be expressed as:

$$
\begin{aligned}
\text { arterial noradrenaline concentration } \\
=\frac{\text { noradrenaline release rate }}{\text { splanchnic noradrenaline clearance }} \\
\quad+\text { extra-splanchnic noradrenaline clearance }
\end{aligned}
$$

In normal subjects, the splanchnic clearance of noradrenaline $(435 \mathrm{ml} / \mathrm{min})$ is approximately one third of the whole body clearance $(1.45 \mathrm{l} / \mathrm{min}),{ }^{15}$ and preliminary studies do not indicate the presence of decreased extra-splanchnic clearance of noradrenaline in patients with cirrhosis (Henriksen et $a l$, unpublished results). Therefore the relatively small decrease in splanchnic noradrenaline clearance, as observed in the present study, is far too small to be the source of the 70-200\% increase in arterial noradrenaline concentration as found in recompensated and decompensated patients.

Thus, the present results suggest that enhanced sympathetic nervous activity, rather than a decreased splanchnic elimination, is the main source of the increased arterial noradrenaline concentration in some patients with cirrhosis.

The kidney released noradrenaline into the systemic circulation in recompensated and decompensated patients as evidenced by a significant renal venous-arterial noradrenaline concentration difference in group II, III and IV patients, but not in controls and compensated patients. The size of the renal noradrenaline release in the supine and resting recompensated and decompensated patients is of the same order as that found by Manheim et al $^{16}$ in normal volunteers during heavy exercise. The release of noradrenaline from the kidney may indicate increased sympathetic nervous activity in this organ, which would be in accordance with animal experiments of sympathetic nerve stimulation to the kidney. ${ }^{17} 18$ It is well established, that kidney function and renal perfusion often are decreased in patients with ascites. ${ }^{19} 20$ This may, at least in part, be a consequence of enhanced sympathetic vasoconstrictor activity, as recently discussed by Ring-Larsen et al. ${ }^{9}$ It should be emphasised, however, that a decreased renal plasma flow per se will augment - but not initiate - the difference between renal venous and arterial plasma concentrations of any substance released from the kidney to the blood at a constant rate. The normal renal extraction ratio of adrenaline, as found in the present study, may suggest that the net release of noradrenaline from the kidney in group II, III and IV patients covers the sum of two unidirectional fluxes (uptake and release). The solution to this complex problem of exact quantification of postganglionic release of neurotransmitter from the kidney must await simultaneous determination of unidirectional flux rates and renal perfusion.

Cirrhosis is associated with a variety of circulatory changes - namely, increased cardiac output, ${ }^{21}$ plasma volume, ${ }^{22}$ heart rate, and possibly muscle perfusion, ${ }^{23}$ whereas arterial blood pressure and renal blood flow are decreased. ${ }^{19}$ Volume and baroreceptor mediated stimuli have been discussed as possible afferent triggers for enhanced sympathetic nervous activity in cirrhosis. ${ }^{4-7}$ In the present study, wedged-minus-free hepatic vein pressure was positively correlated to arterial noradrenaline concentration and to renal venousarterial noradrenaline difference. This may indicate a relationship between splanchnic haemodynamics and sympathetic nervous tone. Another possible explanation is that both are parallel phenomena related to a third variable - for example, hepatic function. The lack of significant correlations between arterial noradrenaline and galactose elimination capacity, indocyanine green clearance, and splanchnic indocyanine green extraction does not speak against this, but might be because of the relatively small numbers of patients studied. Kostreva et $a l^{24}$ found enhanced activity in renal sympathetic nerve fibres in dogs during posthepatic venous outflow block, a condition simulating some of the haemodynamic abnormalities in cirrhosis, and there are strong indications that increased sympathetic tone to the kidney in part may be responsible for increased sodium reabsorption. 6 25-27 Accordingly, raised sympathetic nervous activity in cirrhosis may be regarded as a compensatory mechanism in an attempt to retain water and sodium and to restore systemic haemodynamics, especially systemic arterial blood pressure.

The minor rise of arterial plasma adrenaline 
concentration detected in some patients with cirrhosis may be the consequence of increased sympathetic nervous tone to the adrenal glands and a somewhat decreased hepatic metabolism. The splanchnic area extracted adrenaline more efficiently than noradrenaline in both controls and cirrhotic patients. This could be because of differences in enzymatic activity of the metabolic pathways of adrenaline and noradrenaline,$^{28}$ or may more likely cover a release of noradrenaline from the intestines. In cirrhosis and controls the kidney extracted adrenaline in equal amounts but less than the splanchnic area. The potential effect of increased adrenaline on haemodynamics, glucose and lipid metabolism is unknown.

We conclude that even though net splanchnic elimination of noradrenaline is somewhat reduced in cirrhosis, increased arterial noradrenaline in decompensated and recompensated cirrhosis is only to a limited extent owing to decreased splanchnic elimination. Probably this increase is because of the release of noradrenaline from the kidneys and possibly other organs (adrenal glands, intestine, heart), indicating enhanced sympathetic nervous activity which in part may be responsible for increased sodium retention in the decompensated state of cirrhosis.

This study was supported by grants from the Danish Medical Research Council. It is a pleasure to thank Dr Peer Tfelt-Hansen, nurses, technicians, and Mrs Ruth Werner (secretary) for expert assistance.

\section{References}

1 Engleman K, Portnoy B. A sensitive double-isotope derivate assay for norepinephrine and epinephrine. Normal resting human plasma levels. Circ Res 1970; 26: 53-7.

2 Christensen NJ, Vestergaard P, Sørensen T, Rafaelsen OJ. Cerebrospinal fluid adrenaline and noradrenaline in depressed patients. Acta Psychiatr Scand 1980; 61: 178-82.

3 Christensen NJ. Plasma noradrenaline and adrenaline measured by isotope-derivative assay. Dan Med Bull 1979; 26: 17-36.

4 Henriksen JH, Christensen NJ, Ring-Larsen $\mathrm{H}$. Noradrenaline and adrenaline concentrations in various vascular beds in patients with cirrhosis. Relation to haemodynamics. Clin Physiol 1981; 1: 293-304.

5 Henriksen JH, Ring-Larsen H, Christensen NJ. Plasma noradrenaline in patients with liver cirrhosis in relation to ascites and treatment. Clin Physiol 1981; suppl. 1: $66-70$.
6 Bichet DG, Van Putten VJ, Schrier RW. Potential role of increased sympathetic activity in impaired sodium and water excretion in cirrhosis. N Engl J Med 1982; 307: 1552-7.

7 Bernardo M, Trevisani F, Santini C et al. Plasma norepinephrine, weak neurotransmitters and renin activity during active tilting in liver cirrhosis: Relationship with cardiovascular homeostasis and renal function. Hepatology 1983; 3: 56-64.

8 Arroyo V, Planas R, Gaya J et al. Sympathetic nervous activity, renin-angiotensin system and renal excretion of prostaglandin $E_{2}$ in cirrhosis. Relationship to functional renal failure and sodium and water excretion. Eur J Clin Invest 1983; 13: 271-8.

9 Ring-Larsen H, Hesse B, Henriksen JH, Christensen NJ. Sympathetic nervous activity and renal and systemic haemodynamics in cirrhosis: Plasma norepinephrine concentration, hepatic extraction, and renal release. Hepatology 1982; 2: 304-10.

10 Vendsalu A. Studies on adrenaline and noradrenaline in human plasma. Acta Physiol Scand 1960; suppl. 49: 173.

11 Tygstrup N. Determination of the hepatic galactose elimination capacity after a single intravenous injection in man. Acta Physiol Scand 1963; 58: 162-72.

12 Henriksen JH. Variability of hydrostatic hepatic vein and ascitic fluid pressure, and of plasma and ascitic fluid colloid osmotic pressure in patients with liver cirrhosis. Scand J Clin Lab Invest 1980; 40: 515-22.

13 Winkler K, Tygstrup N. Determination of hepatic blood flow in man by Cardio-Green. Scand J Clin Lab Invest 1960; 12: 353-6.

14 Henriksen JH, Christensen NJ, Kok-Jensen A, Christiansen I. Increased plasma noradrenaline concentration in patients with chronic obstructive lung disease: relation to haemodynamics and blood gases. Scand J Clin Lab Invest 1980; 40: 419-27.

15 Hilsted J, Christensen NJ, Madsbad S. Whole body clearance of norepinephrine: The significance of arterial sampling and of surgical stress. J Clin Invest 1983; 71: 500-5.

16 Manhem P, Lecerof $H$, Hökfelt B. Plasma catecholamine levels in the coronary sinus, the left renal vein and peripheral vessels in healthy males at rest and during excercise. Acta Physiol Scand 1978; 104: 364-9.

17 Unger T, Buu NT, Kuchel O. Renal handling of free and conjugated catecholamines following surgical stress in the dog. Am J Physiol 1978; 235: F542-7.

18 Oliver JA, Peuto J, Sciacca RR, Cannon PJ. Basal norepinepherine overflow into the renal vein: effect of renal nerve stimulation. Am J Physiol 1980; 239: F371-7.

19 Ring-Larsen H. Renal blood flow in cirrhosis: relation to systemic and portal haemodynamics and liver function. Scand J Clin Lab Invest 1977; 37: 635-42.

20 Anonymous. Hepatorenal syndrome or hepatic nephropathy? [Editorial] Lancet 1980; 1: 801-3.

21 Murray JF, Dawson AM, Sherlock S. Circulatory changes in chronic liver disease. Am J Med 1958; 24: 358-67.

22 Lieberman FL, Reynolds TB. Plasma volume in cirrhosis of the liver: its relation to portal hypertension, 
ascites, and renal failure. J Clin Invest 1967; 46: 1297-308.

23 Kontos HA, Shapiro W, Mauch HP, Patterson JL. General and regional circulatory alterations in cirrhosis of the liver. Am J Med 1964; 37: 526-35.

24 Kostreva DR, Castaner A, Kampine JP. Reflex effects of hepatic baroreceptors on renal and cardiac sympathetic nerve activity. Am J Physiol 1980; 238: R390-4.

25 DiBona GF. Neurogenic regulation of renal tubular sodium reabsorption. Am J Physiol 1977; 233: F73-81.
26 Reinhardt HW, Eisele R, Kaczmarczyk G, Mohnhaupt R, Oelkers W, Schimmrich B. The control of sodium excretion by reflexes from the low pressure system. Independent on adrenal activity. Pflügers Arch 1980; 384: 171-6.

27 Bello-Reuss E. Effect of catecholamines on fluid re-absorption by the isolated proximal convoluted tubule. Am J Physiol 1980; 238: F347-52.

28 Kopin IJ. Technique for the study of alternate metabolic pathways; epinehrine metabolism in man. Science 1960; 131: 1372-4. 